\title{
Demand Determinants for Urban Freight Consolidation Center -A Case of Korea
}

\author{
Mohammad Khaled Afzal ${ }^{1}$ and Yong Jin Kim, Ph.D..$^{2^{*}}$ \\ ${ }^{I}$ Department of Management Studies, Chittagong University, \\ Chittagong, Bangladesh \\ ${ }^{2}$ Asia Pacific School of Logistics \& Graduate School of Logistics \\ Inha University, Incheon, South Korea \\ ${ }^{1}$ khaled_afzal@yahoo.com, ${ }^{2} y o n g j i n @ i n h a . a c . k r$
}

\begin{abstract}
Incorrect estimation of demand is one of the key reasons for failures of the urban freight consolidation center (UFCC) which is becoming more popular due to its ability to improve economic, environmental, and social sustainability of the urban freight logistics system. In order to help estimate the true potential demand for UFCC in Korea, this research identified transport company's characteristics that indicate demand for UFCC. Freight transport companies' operational characteristics and their demand response information were collected by survey and in-depth interview. The data were analyzed by rank order correlation and ordered logistic regression. All methods suggest that the estimation of demand for UFCC should be focused on those transport companies that generate large revenue but mainly use light (small and medium) capacity cargo vehicles. Other identified potential users are food and beverage transporters, transporters of distribution companies' goods, container vehicles, and long contracted \& self-owned vehicles. Those companies dealing with container and express parcel deliveries and making predominantly home deliveries could be also a good prospect for UFCC.
\end{abstract}

Keywords: Urban, Freight, Consolidation, UFCC, Demand, Determinants, Transport Companies, Logistics Characteristics, Korea, Rank Order Correlation, Logistic Regression

\section{Introduction}

Transport operations contribute significantly to the problems of congestion, pollution, safety, and noise that make urban areas unattractive [1]. Though the effects on freight transportation on those problems are smaller than passenger transportation, freight vehicles hold the popular perception of being detrimental to the urban environment [2-4]. The transportation of goods consumes $40 \%$ of total urban oil consumption and produces $20-30 \%$ of vehicle kilometers and is responsible for over 16-50\% of air pollution in urban area $[2,5$, 6]. Accident rates are two times higher in urban areas, with trucks being involved in $10 \%$ of serious injuries [2]. Over 5\% to $10 \%$ fatal accidents involve light commercial trucks, and $10 \%$ to $15 \%$ involve heavy commercial trucks [5]. An improvement in urban freight transportation will certainly improve the quality of life in urban areas.

The stakeholders of urban freight transportation entities such as shippers, transport/ logistic companies, government organizations, and the community each possess diverse interests on

\footnotetext{
* Corresponding Author
} 
urban freight transportation operation. Shippers just like to have on time collection/delivery but regret the freight vehicles that occupy the parking spots of a potential customer [7]. They also dislike the time lost loading and unloading goods during business hours. From the point of view of the logistic companies, transport companies like to have free access and a 24-hours delivery window but dislike road congestion, vehicle entry restrictions, and waiting time at factory/stores. Last but not least, the government and community want to have minimal noise, minimal emissions, minimal congestion, and few traffic accidents in order to have a healthy urban quality of life. The UFCC is such a popular solution for urban freight transportation problems that can satisfy economic, environmental, and social sustainability goals and at the same time can (theoretically) benefit all three groups of stakeholders mentioned.

UFCC is a shared-use logistics facility that offers freight transport companies the opportunity to deliver their freights jointly to restricted and/or congested urban areas. It can contribute by reducing the vehicle-km, the time vehicles spend on the road, the number of stops, peak time operations. Additionally, it can increase the truck load and can offer 24/7 service. Other benefits include the environmental ones reducing emissions and fuel consumption, as well as in societal by reducing pollution-related illness, road accidents, and land loss.

Being a very much urbanized country, Korea can benefit greatly from UFCC in its freight transport. Compared to other modes of transportation, Korean cities are better connected by expressways and local roads; most deliveries into the cities are made through road transportation. However, the increase in the number of cars result decrease in auto speed, increase in congestion, air pollution and parking lot problems [8]. In accordance with Korean freight transport policy, UFCC can increase vehicle utilization, and is centered on a consolidation strategy that is already practiced on a large scale in Korea in the forms of inland freight terminals (IFT), inland container depots (ICD), logistics complexes, joint collection, and delivery centers etc. Implementing UFCC in Korea should be easier than any other similar initiative.

Unfortunately, the instances of sustainable UFCC are very few. Kohler (2004) mentioned that approximately 200 schemes were either planned or carried out in Germany whereas Nobel (as cited by Browne et al., 2005) noted only 5 UFCC schemes are in operation in 2005 in Germany. A survey by Browne et al. (2005) identified 67 feasibility research, pilot/trail, or fully operational UFCC initiatives. Only 27 out of those 67 were operating till 2005. However, the initiatives for building new UFCCs are still continuing at a full pace [11]. Unless success can be ensured, most new initiatives will not be able to achieve their objectives. One of the major reasons for initiatives failing comes from a lack of properly understanding demand for UFCC [6, 10]. According to Takahasi and Hyodo (1999), the theoretical initiatives usually assume a far higher level of demand for UFCC, resulting in often misguided feasibility tests. All transport companies are not suited for UFCC, and similarly, all goods are not feasible for handling at UFCC. Therefore, this research was designed to properly understand the nature of customers, and the freights that possess a good demand for UFCC, which in crucial for its success. The key questions involved include: "What attributes of Korean logistics companies are significantly related with demand for UFCC?" and "What types of commodities are suitable for UFCC in Korea?" Unlike the IFT \& ICD-based top-down approach of improving freight transportation in Korea, UFCC is a bottom-up approach in which consolidation comes from end customers' point of view). In addition, UFCC will also reduce pollution, congestion and emission in the urban areas. 


\section{Background}

\subsection{Urban Freight Consolidation Center}

The Urban Freight Consolidation Center is a logistics facility established for facilitating customer-based consolidation of urban deliveries of various transport companies with the intention of joint distribution. Such a facility offers freight transport companies the opportunity to handover their goods to UFCC at their own convenience in order to deliver to customers located in a busy and/or restricted part of the city. The UFCC is generally located near the border of the service area and carries out consolidated deliveries in an environmentally-friendly vehicle, contributing significantly to green logistics initiatives, too.

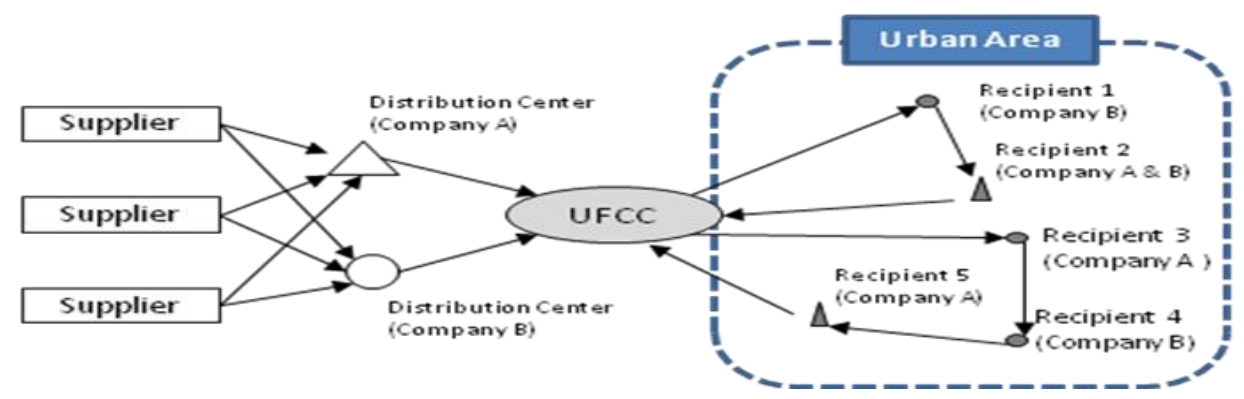

Figure 1. Operation of UFCC in Urban Area [20]

A European Commission initiative for improving urban freight transportation, BEST Urban Freight Solution (BESTUFS) defined UFCC as "A logistics facility situated in relatively close proximity to the geographic area that it serves (be that a city center, an entire town, or a specific site such as a shopping centre), to which many logistics companies deliver goods destined for the area, from which consolidated deliveries are carried out within that area, in which a range of other value-added logistics and retail services can be provided" [1]. Scholars use many synonyms for UFCC such as public distribution depot, urban transshipment center, shared-user urban transshipment depot, city logistics, logistics center, freight village etc. There can be many types of UFCC: some are public initiatives, some are private, and some are public-private joint venture. The operations are publically financed most of the time and sometimes self-financed. Normally single professional third-parties operate a UFCC, but there have also been multiple operators. Logistics/transport companies are the main customers for UFCC. However, one initiative in the Netherlands has had success by targeting retailers [24]. In most of the cases, participation in UFCC services is voluntary, but some initiatives such as Heathrow Airport UFCC, Monaco UFCC, made it compulsory. Some UFCC use low-emission or electric vehicles, but some in Germany and Japan have proven successful even after using conventional delivery vehicles.

Operations of a UFCC are often difficult to distinguish from that of retail distribution centers (DC), intermodal terminals, and distribution hubs. In contrast to a typical distribution center of a company, a UFCC is managed and operated by a neutral company and jointly delivers freights of multiple delivery companies. Its environmental and social objectives dominate those to improve economic efficiency. Compared to an integrated freight terminal (IFT), inland container depot (ICD), or regional hub that are normally located at suburban areas, the operating of a UFCC is much smaller. The IFTs and ICDs are regional logistics hubs that offer support facilities (such as places for breaking bulks, cross docking, storage, container repair and storage, collection, clearance, delivery handling, gas, vehicle repair and 
washing, etc.,) to both resident and non-resident manufacturing and logistics companies. Each company performs collection and delivery operations independently, resulting in redundant delivery tours to the same end customer. On the other hand, a UFCC consolidates freights of multiple delivery companies based on drop points, distributing jointly and thus avoids redundant delivery tours to an urban customer. End customer-based consolidation requires a UFCC to be located in close proximity to its urban customers. According to previous research, the average distance of a UFCC from its service area was found to be less than 10 $\mathrm{km}$.

Previous research into UFCCs can be categorized as concept enlargement studies, impact analysis studies, case studies, and demand analysis. The concept enlargement studies explain the definitions, classification, implementation, and evaluation methodologies of UFCC $[1,2$, $4,7,10,13,14,15]$. Impact analysis studies evaluated UFCC's contribution to the environmental, social, and economic improvement [10, 16, 17, 18, 19, 20, 21]. Case studies conducted feasibility studies and identified critical success or failure factors of previous UFCC initiatives [9, 11, 21, 22, 23, 24]. Studies related to demand for UFCC focused on the important factors regarding location [25, 26, 27, 28, 29], potential customers [3], favorable transport cost structure [6], and demand for UFCC in relation to vehicle capacity, population density, cost structure, and coverage area [20].

Regan and Golob (2005) examined California trucking companies in order to identify potential customers (transport companies) for UFCC. They analyzed the trucking companiesstated preference for a UFCC with their operating attributes to identify which types of transport companies would demand UFCC services. Marcucci and Danielis (2008) looked mostly at Italian traders to determine the level of urban freight transport-related costs and services that would make UFCC preferred over private delivery. Taniguchi et al., (1999) focused on the size and location of a UFCC based on total freight traffic flows. Young et al., (1980), Ogden and Young (1984), and Zhang et al., (2011) tried to identify factors and relative weights important in determining a UFCC location by using a multinomial logit model, elimination by aspect model, and AHP models, respectively. Kawamura and Loo (2008) highlighted the demand for a UFCC considering alternative cost, population density, coverage area and delivery vehicle size by optimizing respective cost functions. In order to gauge demand for a UFCC in Korea, the first task involves identifying the customers who possess the demand for a UFCC. If the customers and the commodity type suitable for UFCC can be properly identified, the volume of demand will be possible to estimate later with greater accuracy.

\subsection{Korean Urban Transportation and Collaborative Initiatives}

Korean logistics industries made a massive leap starting in 1995. As a percentage of GDP, logistics costs dropped from 16.5 (1998) to 12.5 (2008) [30]. Road transport (except parcel delivery) (17.7\%) and parcel delivery (11.7\%) became the first and second freight transport growth sectors in 2011 as compared to 2010 [31]. The Latest surveys by KOTRA on trade associations to promote foreign UFCC found that out of 312 companies, 224 companies (78.2\%) had no idea about such initiatives, with smaller companies being less aware than larger corporations by 8 points. In 2001, over $14.9 \%$ companies in Korea were found to be using some kind of joint logistics systems, and $36.7 \%$ were receptive to it, a number that is steadily increasing. Distribution companies prefer to use UFCC rather than manufacturing companies (30.4\% and $12.9 \%$, respectively). Larger companies are found better user $(19.1 \%)$ than small- and medium- sized companies (SME) (11.5\%). However manufacturing companies were found to be slightly more interested $(22.1 \%)$ to use such facilities than 
distribution companies (19.6\%). When looking at specific industries, paper, print, and publishing industry had the highest interest at $23.8 \%$.

Korean companies are performing many kinds of collaborative functions voluntarily or under the encouragement of ministries. These joint logistics are initiated either by private companies or public institutions, and lead to a reduction in logistical costs and/or improve the level of service. Most of the public initiatives targeted to consolidate the freights of smalland medium- enterprises (SMEs) are located within or nearby a locality to make them competitive against big companies. Interestingly, in a 2001 survey, big companies were found to be more interested than SMEs in using those facilities. Different types of Korean initiatives include integrated freight terminals (IFT), inland container depots (ICD), logistics complexes (distribution complexes), general cargo terminals, joint collection and delivery centers, agrofisheries distribution centers, airport and sea hinterland complexes, rail yards, industrial complex freight consolidation centers [32]. Among the public logistics facilities, joint collection and delivery centers, the industrial complex freight consolidation center possessed characteristics similar to a UFCC. Joint collection and delivery centers(also called a Home Delivery Complex) were built analyzing urban district cargo volume and location characteristics, and consolidates freights based on delivery criteria. In 2009, five complexes were completed, one was under construction, and one was abandoned [32]. Industrial complexes were established to offer logistical support services, consolidated delivery service between complexes, or for shippers residing inside the complex or nearby localities, with two currently running at Shihwa of Gyoungi-do and Changwon of Gyoungsungnam-do. Recently, interest has developed in private consolidation/joint logistics system located inside an industrial complex, port, or similar logistics facilities. Since 2005, Inside Nam-dong industrial complex, professional logistics company Sumyoung Logistic Ltd., are practicing joint logistics business targeting 3600 small- and medium-sized companies residing inside the complex. In Yosu City, rear to the harbor, storage, delivery, grouping, fabrication and processing kind of value added activities are also performed by joint logistics centers.

Some common characteristics can be drawn considering all these public, private, and public-private initiatives. All of them are aimed at reducing logistics cost and/or improving the level of service, and not at all taking into consideration the social and environmental benefits. As a result, feasibility analysis only includes economic gains. Most of the schemes offer diversified logistics services together with consolidated freight transportation. In addition to joint transportation and storage, efficiency was expected to increase due to performing all kinds of required logistics services within close proximity. Some of the initiatives are confined to specific industry only. Services offered mostly within a complex or between the complexes for which only resident or nearby companies can gain most of the benefits. However, there is no initiative dedicated solely to consolidated delivery in specific congested urban business pockets. Current complexes are operating on a much larger scale than in the Western theoretical UFCC concept. Some of these logistics complexes have now changed its nature by providing space for personal consolidation of individual resident companies, changing from its original aim to achieve cross-company consolidation.

The freight industry in Korea is divided into four categories: general/common freight transport, personal freight transport, delivery cargo transport, and parcel transport (Home delivery). Those four freight categories are carried by either commercial freight vehicles or by non-commercial freight vehicles. The number of non-commercial freight vehicles is higher than commercial freight vehicles. But the average growth rate of commercial freight vehicles is higher than the other. A unique characteristic of the Korean freight vehicle industry is that privately-registered commercial vehicles are often contracted with broker companies in carrying commercial goods under an "Owner-driver system: Jiy-Yip system." Commercial 
freight vehicles in Korea are categorized into two types: freight vehicles and special vehicles. Freight vehicles are classified as general vehicles (also called cargo vehicles), dump vehicles, vans type vehicles, and special purpose vehicles (e.g., tanker, tank lorry, pulls car, cargo bed type vehicles, low floor vehicles, flatbed, container chassis etc.,) [31]. Among those categories, most of the freights are transported through cargo vehicles, dump trucks, special operation vehicles (Tank lorry etc.), and container trailer kind of freight vehicles. The capacity of those cargo vehicles ranges from less than 1 ton to more than 20 tons.

There are basically two types of commercial freight transport companies in Korea: brokerage companies and individual carrier companies. The individual carrier companies are normally small truck owners having few personally-owned freight vehicles. Most of them are also registered with other big brokerage companies. Similarly many brokerage companies also own their own freight vehicles. Thus, the commercial freight transport vehicles of Korea can be found operating under three kinds of vehicle ownership styles: company-owned freight vehicles, long-term (more than 1 month) contracted freight vehicles and short-term (1 month or less) contracted freight vehicles.

The freights in Korea are officially classified into 33 categories (32 plus etc., categories). However, those 32 categories excludes parcel, waste material, post, and house moving freights whereas parcel has become the second largest growth sector of freight transportation in Korea. Though transport companies haul more than one kind of goods, they can be attributed to a kind that they haul most. Different kind of goods classification was used by many previous researchers. The classification of freights we used for this research is given in Table 1 of the Appendix. Main origins and destinations of freights of Korean transport companies are ports (airport, seaports), corporations (manufacturing, mining, distribution and service companies), logistics complexes (industrial complexes, agricultural complexes, Inland Freight Terminals, Inland Container Depots), warehouses, and individual traders/companies/construction sites/households. The area of operations of the carrier companies' can be linked with administrative jurisdictions of Korea. South Korea is divided into 8 provinces (do), 1 special autonomous province (teukbyeoljachido), 6 metropolitan cities (gwangyeoksi), and 1 special city (teukbyeolsi). These provincial level classifications are subdivided into a variety of smaller metropolitan level entities such as cities (si), counties (gun), and districts (gu) which are further subdivided into towns (eup), townships (myeon), neighborhoods (dong) and villages (ri) based on population. For clear distinction on the frontier of operations, transport companies can be attributed as national, provincial, or district-based operational companies based on their mode of length of operations.

\subsection{Freight Demand Modeling Approaches}

Freight demand has been modeled in a number of ways. Harker (1985) divided them into econometric models, spatial price equilibrium models, and network equilibrium models. Econometric models compute freight demand as a correlative and cause and effect relationships to various factors. Correlation can be computed by using Pearson's productmoment correlation coefficient or Spearman rank order correlation coefficient depending on the nature of data. Cause and effect relationships are generally revealed by regression analysis. For the discrete outcome the available regression methodologies are binary, multinomial, and ordered logistic regression. Network equilibrium models apply optimization rules to an objective function that predict the distribution of freight traffic. A thorough review of econometric models and network equilibrium models can be found in Zlatoper and Austrian (1989) and Crainic (1987) respectively. Review over spatial price equilibrium approaches can be found in Friesz et al., (1985) and Harker and Friesz (1986a and 1986b). Winston (1981) proposed categories are aggregate models and disaggregate models. 
Aggregate models use geographical aggregate share as basic units for analysis whereas disaggregate freight demand models consider individual decision maker's choice as a decision making units. The aggregate models use a cost minimization approach and disaggregate models focus on decision maker's behavioral approaches. Based on the nature of decision outcome, freight demand models can also be classified into continuous models and discrete choice models. Continuous models are optimized by calculus methods and discrete choice models use probability to reveal the chance of getting discrete outcomes.

\section{Research Framework}

In order to identify the potential customers and feasible products for a UFCC in Korea, we have to select the appropriate data set (population) first, attributes for data classification, a method to measure demand, and an analysis method.

\subsection{Population Selection}

Freight transportation can be modeled from vehicle movements or a commodity movements' perspective. Commodity movement perspective is more authentic since vehicle movements are induced by the necessity of moving commodities. There are two main kinds of freight movements: The first is the customer's (private or business end-consumers) collection of goods from the upper stream member of the supply chain for purpose of consumptions. Second is the push of freights by the supply chain members to a downstream logistics points for further processing (e.g., stocking, resale).

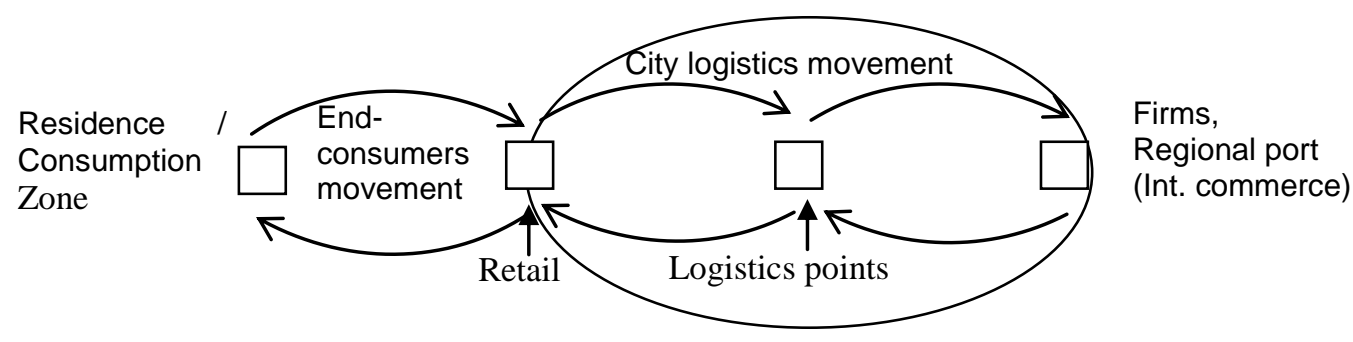

Figure 2. Urban Freight Movement System

Based on the types of distribution channel used there could be many intermediate logistics points in the push movement between producers and retailers such as agent, distribution center, warehouse, wholesaler etc. Though e-commerce can pull the product even directly from the producers, the distribution of those products normally follow regular distribution channel except retailer. The decision-maker for the second type of freight movements and mode choices are shippers or transport companies (such as 2PL or 3PL). The number of receipts by each end consumer in each delivery is relatively too small to get the benefit of consolidation. So the end consumer's freights should not be feasible demand for a UFCC. Though business consumers such as big construction companies, hotels, etc., are relatively high in consumption, but they are normally fed by a push movement (i.e. delivery decision is made by the shipper or transport companies). Since the volume and number of deliveries received by each retailer from different shippers is relatively high, there is a good prospect for getting the consolidation benefit of UFCC. The deliveries to those business consumers or retailers are carried out either by private transports or by hired transports which a UFCC wants to consolidate. As a result, in this research the transport companies were selected as population for surveying the demand for UFCC. Though the registered number of personal 
freight vehicles that are mostly used by manufacturing companies are higher than the registered number of commercial freight vehicles in Korea [30], the percentage of participation of commercial vehicles in previous large-scale consolidations (e.g., IFTs) in Korea is highest [40]. So the commercial freight vehicles are selected as population for primary survey.

\subsection{Selection of Attributes}

Based on the analysis of Korean urban transportation and collaborative initiatives, Korean transport companies are categorized on the basis of their general characteristics, vehicles characteristics, freight characteristics, and delivery characteristics. Under the general characteristics, classification dimensions include size (number of employees, revenue), experience, location, and decision-makers' status. In the case of vehicle characteristics, the classification dimensions were the number of vehicles, revenue by types of vehicles, ownership of vehicles, and length of haul. For freight characteristics, classification dimensions were the level of assortments of goods per delivery, most delivered goods, number of shippers used, and types of shippers. Lastly, under delivery characteristics, the dimensions were origin and destination of freights and levels of consolidation at their final deliveries. Dimension and attributes were tried to match previous researches related with Korean urban transportation.

\subsection{Demand Measuring Scale}

There was no UFCC in Korea, and Korean collaborative initiatives were consolidating individual transport/logistics companies' freights. So the time series data was absent and cross sectional data was irrelevant. In those circumstances, the stated preference survey is a good measurement, with responses being either numbers or nominal. Asking for what portion of deliveries that the respondents want to channel through a UFCC would be unproductive since the cost and location data was not associated. The cost and location data could identify the location and level of demand. Our objective, however, was to identify the potential customers and not the place or level of demand, meaning the nominal response was preferred. The nominal answer can be binary, ordinal, or scale. Binary responses include only a "yes" or "no" to use UFCC. Behavioral studies with binary answers would limit our respondent's ability to express their preferences clearly. Ordinal responses, on the other hand, allow for more than two nominal responses and also express the order of demand. Scale data would be better but not selected in order to avoid difficulties in specifying accurate the level of attraction (scale data) since the UFCC concept was new to Korean transport companies, and cost and location data were also absent. In that case, there were three ordinal responses in the form of "do not use a UFCC (No)," "may use a UFCC (May be)," and "will use a UFCC (Yes)" as a response to the question "Does your company have any desire to use a UFCC(Urban Freight Consolidation Center)?”

\subsection{Model Choice}

In order to identify the attributes of transport companies that cause demand for a UFCC has suggested using econometric models. The ordinal nature of the demand response and mostly dichotomous company attributes indicated to use Spearman rank order correlation coefficient. Similarly discrete and ranked nature of demand responses (dependent variable), nominal and binary nature of attributes/dimensions (independent variables) suggested ordered logistic regression for cause and effect analysis. 
The outcome variable could have any one of the three nominal value "No", "May be", or "Yes". Since "No" means no demand for UFCC and "May be" and "Yes" means gradually more demand, we denoted our dependent variable by $\mathrm{YK}$, where $\mathrm{K}=\{0,1,2\}$ and "No"=0; "May be"=1; and "Yes"=2. The observed (independent) variables were the dimensions and in some case the attributes within the dimensions. These observed variables are many types and presented as $-\mathrm{Xij}=$ where as ' $\mathrm{i}$ ' is the indices for dimension and ' $\mathrm{j}$ ' is the indices for attributes (if available) within ith dimensions. Depending upon the characteristics of the observed variable the value of Xij could be binary $\{0,1\}$, ordinal $\{0,1,2,3 \cdots\}$ or continuous.

Hence the ordered logistic regression model was,

Cumulative Logit model $(\log$ of odds $)=\ln \left(\frac{\operatorname{Pr}\left(Y_{k}\right)}{1-\operatorname{Pr}\left(Y_{k}\right)}\right)=\alpha_{\mathrm{j}}-\beta_{\mathrm{ij}} X_{\mathrm{ij}}$

Where,

$\mathrm{Y}_{\mathrm{K}}=\left\{\mathrm{Y}_{0}, \mathrm{Y}_{1}, \mathrm{Y}_{2}\right\}$

$\beta_{\mathrm{ij}}=$ Parameter of $j^{\text {th }}$ attribute of $i^{\text {th }}$ dimension

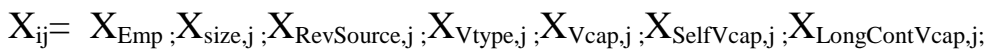

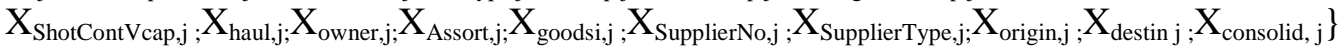

$\mathrm{X}_{\mathrm{Emp}}=$ Continuous variable representing number of employees

$X_{\text {size }, j}=$ Ordered nominal variable for the size of the company based on revenue.

Here, $\mathrm{j}=\{$ Over $1000 \mathrm{M}, 500-1000 \mathrm{M}$, below 500 $\}$

$\mathrm{X}_{\mathrm{RevSource}, \mathrm{j}}=$ Nominal variable denoting main source of revenue;

Here, $\mathrm{j}=\{$ Cargo, Special Vehicle, Container $\}$

$\mathrm{X}_{\mathrm{Vtype}, \mathrm{j}=}$ Nominal variable denoting types of most of the vehicle;

Here $\mathrm{j}=\{$ Cargo, Special Vehicle, Container $\}$

$X_{\mathrm{Vcap}, \mathrm{j}}=$ Ordered variable denoting total vehicle's capacity; Here $\mathrm{j}=\{$ Heavy, medium, small $)$

$\mathrm{X}_{\text {SelfVcap }, \mathrm{j}}=$ Ordered variable denoting Self owned vehicle capacity;

Here $\mathrm{j}=\{$ Heavy, medium, small $\}$

$\mathrm{X}_{\text {LongContVcap, } \mathrm{j}}=$ Ordered variable denoting long contracted vehicle capacity;

Here $\mathrm{j}=\{$ Heavy, medium, small $\}$

$\mathrm{X}_{\text {ShortContVcap, } \mathrm{j}}=$ Ordered variable denoting short contracted vehicle capacity;

Here $\mathrm{j}=\{$ Heavy, medium, small $)$

$X_{\text {haul }, j}=$ Ordered nominal variable for major haul lengths;

Here $\mathrm{j}=\{$ within city, within province, domestic long distance $\}$

$\mathrm{X}_{\mathrm{owner}, \mathrm{j}}=$ Ordered nominal variable explain strength of control (ownership) over vehicles;

Here $\mathrm{j}=\{$ self owned, long contracted, short contracted $\}$

$\mathrm{X}_{\text {Assort }}=$ Ordered nominal variable for extent of assorted goods carried

Here $\mathrm{j}=\{1,2-5,6-9,10-13\}$

$\mathrm{X}_{\text {goods, } \mathrm{j}}=$ Variables denoting major type of goods haulage; Here goods $=\{$ Appendix $A\}$,

$\mathrm{X}_{\text {Supplier }, \mathrm{j}}=$ Ordered nominal variable for number of freight providers used;

Here $\mathrm{j}=\{0-5,6-20,21-50,51-100,100$ above $\}$

$\mathrm{X}_{\text {SupplierType, } \mathrm{j}}=$ Nominal variable denoting fright provider type;

Here $\mathrm{j}=\{$ Vendor / Other transport company /Co-operatives, Manufacturing companies, Distribution companies, Final customer (Home, company) \}

$X_{\text {origin }, j}=$ Nominal variable denoting origin of freights;

Here $\mathrm{j}=\{$ Manufacturing Co. (Plant, warehouse)), Distribution Co. (Show room, Store), 
Ports, ICD/ Railroad CY, Other region Logistics/Freight terminal, Final Consumer (Home, Company), Others $\mathrm{X}_{\text {destin, }}=$ =Nominal variable denoting destination of freights;

Here $\mathrm{j}=\{$ Manufacturing Co. (Plant, warehouse), Distribution Co. (Show room, Store),

Ports, ICD/ Railroad CY, Other region Logistics/Freight terminal, Final Consumer (Home, Company), others $\}$

$X_{\text {consolid, }}=$ Ordered nominal variable for extent of delivery consolidation; Here $j=\{1,2-4,6-10$, 11-20, 20 above $\}$

\section{The Samples}

Transport companies were e-mailed questions regarding their general business information (respondents' IDs, company size, etc.), freight vehicle-related information, freight related information, deliver related information, and state demand for UFCC services. A total of 14 main questions were arranged in both a multiple choice and fill in the blank format. A discussion about the UFCC and its distinction from IFT and typical DC preceded the questions in order to help the respondents grasp the real picture. The questionnaire was prepared in Korean language for easy understanding of the respondents. The electronic response rate was not very much satisfactory and hence in-depth interviews were conducted with the prospective respondents regarding the questionnaires and related issues in their office.

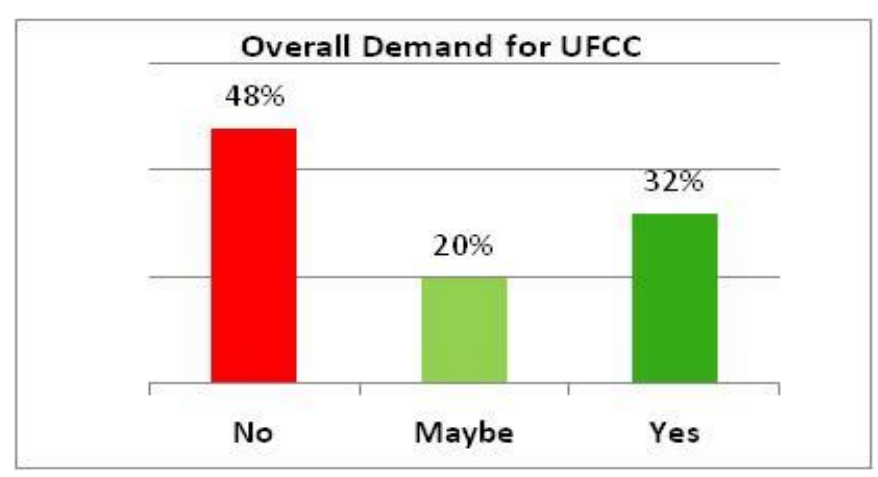

Figure 3. Stated Demand for UFCC in Korea

Among the fifty completed responses, $48 \%$ replied to have no intention to use of UFCC, but $32 \%$ said "yes," and another $20 \%$ responded "maybe." Since most of the respondents are from the capital region, location-based classification is suspended and some categories were collapsed to avoid empty cells in cross tabulation. The outcome of the survey was analyzed with descriptive statistics, correlation theory, and ordered logistic model.

\section{Results}

\subsection{Descriptive Relationships}

The respondents' demand responses for UFCC were first arranged according to the dimensions and attributes to visualize descriptive relationships. Table 1 presents different dimensions, corresponding attributes, and respective percentage of positive demand for UFCC. 
Table 1. Percentage of Demand for UFCC to Transport Companies Attributes

\begin{tabular}{|c|c|c|c|}
\hline $\begin{array}{r}\text { Dimensions / } \\
\text { Attributes }\end{array}$ & $\begin{array}{c}\text { Positive to UFCC } \\
\text { ( Yes +Maybe) }\end{array}$ & $\begin{array}{c}\text { Dimensions / } \\
\text { Attributes }\end{array}$ & $\begin{array}{c}\text { Positive to UFCC } \\
\text { ( Yes +Maybe) }\end{array}$ \\
\hline Company revenues & $\begin{array}{c}\text { Below } 50 \mathrm{~B} \text { won }=43 \% \\
\text { Over } 50 \mathrm{~B} \text { won }=82 \%\end{array}$ & $\begin{array}{c}\text { Dominant freight } \\
\text { origins }\end{array}$ & $\begin{array}{c}\text { Manufacturing co. }=52 \% \\
\text { Distribution co. }=60 \% \\
\text { Terminals and ports }=43 \%\end{array}$ \\
\hline $\begin{array}{c}\text { Dominant revenue } \\
\text { Source }\end{array}$ & $\begin{array}{l}\text { Cargo vehicle }=48 \% \\
\text { Container }=57 \% \\
\text { Special vehicle }=67 \%\end{array}$ & $\begin{array}{l}\text { Dominant freight } \\
\text { destinations }\end{array}$ & $\begin{array}{c}\text { Manufacturing Ent. }=44 \% \\
\text { Distribution Ent. }=50 \% \\
\text { Terminals and ports }=50 \% \\
\text { Home Delivery }=75 \%\end{array}$ \\
\hline $\begin{array}{c}\text { Dominant vehicle } \\
\text { types }\end{array}$ & $\begin{array}{c}\text { Cargo vehicle }=51 \% \\
\text { Container vehicle }= \\
75 \% \\
\text { Special vehicle }=100 \%\end{array}$ & $\begin{array}{c}\text { Level of consolidation } \\
\text { in final } \\
\text { delivery }\end{array}$ & $\begin{array}{c}1 \text { drop }=78 \% \\
2 \text { to } 5 \text { drop }=67 \% \\
6 \text { to } 10 \text { drop }=33 \% \\
11 \text { to } 20 \text { drop }=67 \% \\
\text { Over } 20 \text { drop }=67 \%\end{array}$ \\
\hline $\begin{array}{c}\text { Dominant vehicle } \\
\text { ownership } \\
\text { type }\end{array}$ & $\begin{array}{c}\text { Self-owned }=57 \% \\
\text { Long contracted }= \\
38 \% \\
\text { Short contracted }=65 \%\end{array}$ & \multirow{6}{*}{ Categories of freights } & \multirow{6}{*}{$\begin{array}{c}\text { The primary industry }=60 \% \\
\text { Food } \& \text { Beverages }=80 \% \\
\text { Fiber. Clothing }=67 \% \\
\text { Wood, paper, } \\
\text { publications }=33 \% \\
\text { Petrochemical }=60 \% \\
\text { Non-metallic material }=33 \% \\
\text { Steel }=29 \% \\
\text { Machine }=40 \% \\
\text { Electric and Electronic }= \\
50 \% \\
\text { Transport Equipment }=0 \% \\
\text { Other }=50 \% \\
\text { Non-manufacturing }=\mathrm{N} / \mathrm{A} \\
\text { Containers, Courier }=83 \%\end{array}$} \\
\hline $\begin{array}{r}\text { Dominant capacity } \\
\text { of cargo } \\
\text { vehicles }\end{array}$ & $\begin{array}{l}\text { Heavy }=24 \% \\
\text { Light }=72 \%\end{array}$ & & \\
\hline $\begin{array}{r}\text { Dominant haul } \\
\text { length }\end{array}$ & $\begin{array}{c}\text { Short haul }=60 \% \text { Medium } \\
\text { haul }=58 \% \text { Long } \\
\text { haul }=49 \%\end{array}$ & & \\
\hline Freight mix & $\begin{array}{c}1 \text { category }=20 \% \\
\text { to } 5 \text { Categories }= \\
64 \% \\
6 \text { to } 9 \text { Categories }=50 \% 10 \\
\text { to } 13 \text { categories } \\
=53 \%\end{array}$ & & \\
\hline $\begin{array}{l}\text { Number of freight } \\
\text { provider }\end{array}$ & $\begin{array}{c}50 \& \text { Below }=40 \% \\
51 \text { to } 100=71 \% \\
\text { Over } 100=65 \%\end{array}$ & & \\
\hline $\begin{array}{r}\text { Dominant freight } \\
\text { suppliers }\end{array}$ & $\begin{array}{c}\text { Vendor / Other transport } \\
\text { company } / \mathrm{Co}- \\
\text { operatives }=38 \% \\
\text { Mfg. companies }=53 \% \\
\text { Distribution } \\
\text { companies }=83 \%\end{array}$ & & \\
\hline
\end{tabular}

Over $82 \%$ of larger companies (Yearly revenue is over $50 \mathrm{~B}$. won) were found interested for UFCC services. Besides companies having larger share of container or special vehicles were found having more than average interest for UFCC. Among the different types of vehicles ownership styles and capacities, companies with mostly short-term contracted and light vehicles were found to be more interested (65\% and $72 \%$, respectively) than other attributes. Short- and medium-haul companies have shown more interest than long-haul companies. Freight mix did not shown an incredibly high or low percentage for demand for a UFCC, however companies with higher number of shippers were more interested for UFCC. Manufacturing shippers did not show very much preference for UFCC, however most of the broker companies (62\%) disliked UFCC services. Though distribution companies possessed more demand for UFCC (83\%). Among the others categories, container and express parcel 
category freights movers demonstrated an interest (83\%), followed by foods and beverage (80\%), and then fiber \& cloth (67\%). Other categories showing slightly positive responses were primary industry $(60 \%)$ and petro-chemical $(60 \%)$. Steel $(29 \%)$, non-metallic materials (33\%), wood, paper \& publication category $(33 \%)$, machine category $(40 \%)$ movers were negative to the demand for a UFCC, meaning food \& beverage and parcel are the most feasible goods.

\subsection{Correlation between Transport Companies' Attributes and Demand for a UFCC}

Identifying relationships between the demand for a UFCC and logistics dimensions/attributes from descriptive analysis was not very reliable due to quantity weight of each data set. Correlation coefficient was more useful in this situation. Demand responses were already ordinal. Transport companies attributes that are ordered in nature were directly usable in the Spearman rank order correlation model, but other nominal attributes of dimensions were converted into dichotomous variables (presence equals " 1 " representing higher order and absence is " 0 " which is lower order) for making them adaptable in the model. The statistical package SPSS version 17 was used for data analysis. The Spearman correlation module provides coefficient of correlation and corresponding level of significance of data. At a strict scenario of 5\% level of significance, 4 dimensions/attributes have shown significant correlation with the demand for UFCC. The dimensions are company size, vehicle capacity, and types of supplier.

\section{Table 2. Rank Order Correlation between Demand for a UFCC and Transport Companies Attributes at 5\% Level of Significance}

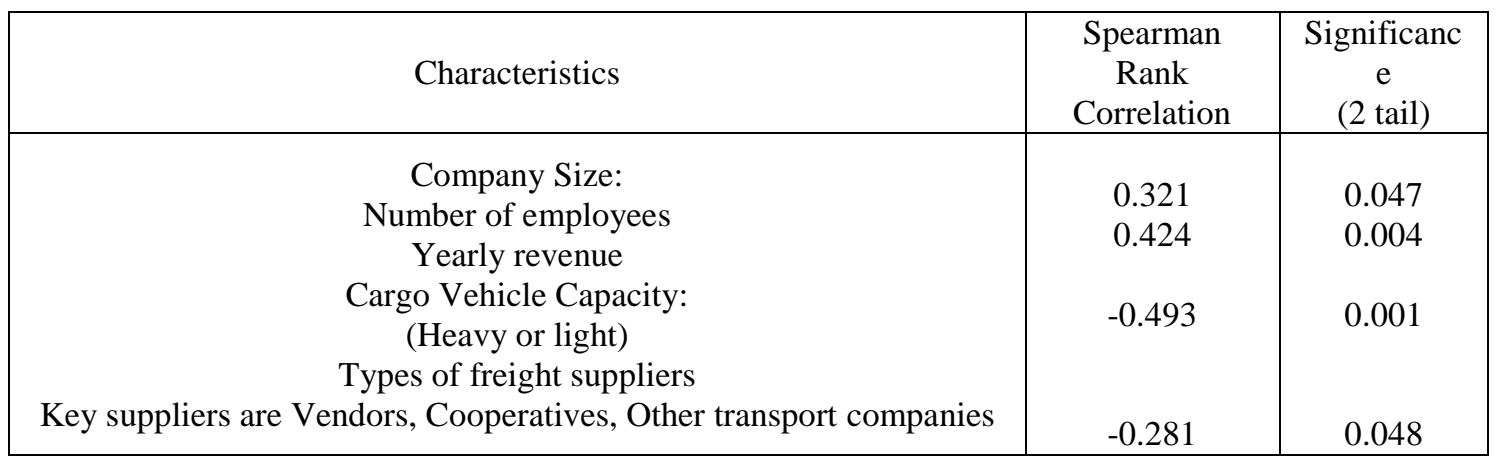

If the level of significance is relaxed to $15 \%$, some other interesting characteristics become significant. The five new entrants in the significant list are major portion of revenues from cargo vehicles, major portion of revenues from container vehicles, vehicles ownership style, freights are foods and beverage, and key suppliers are distribution companies.

Both the number of employees and yearly revenue attributes measure the size of the company and they are also mutually significantly correlated (0.845). In our later analysis, we will use only one of them to avoid redundancy. Based on the results of the coefficient of correlation, the variables will be easier to identify (attributes or dimensions) that are significantly associated with the demand for UFCC. The next step is to estimate the cause and effect relationship to determine which of these dimensions/attributes are keys in identifying potential user of UFCC. 
Table 3. Rank Order Correlation between Demand for UFCC and Transport Companies Attributes at $15 \%$ Level of Significance

\begin{tabular}{|c|c|c|}
\hline Characteristics & $\begin{array}{c}\text { Spearman Rank } \\
\text { Correlation }\end{array}$ & $\begin{array}{l}\text { Significance } \\
(2 \text { tail })\end{array}$ \\
\hline $\begin{array}{l}\text { Company Size: } \\
\text { Number of employees } \\
\text { Yearly revenue }\end{array}$ & $\begin{array}{l}0.321 \\
0.424\end{array}$ & $\begin{array}{l}0.047 \\
0.004\end{array}$ \\
\hline $\begin{array}{l}\text { Vehicle Characteristics: (Revenue source) } \\
\text { Major revenue source is from Cargo V. } \\
\text { Major revenue source is from Container }\end{array}$ & $\begin{array}{r}-0.239 \\
0.252\end{array}$ & $\begin{array}{l}0.098 \\
0.080\end{array}$ \\
\hline $\begin{array}{c}\text { Vehicle Characteristics : (Capacity) } \\
\text { (Heavy or light) }\end{array}$ & $\begin{array}{l}-0.493 \\
0.228\end{array}$ & $\begin{array}{l}0.001 \\
0.128\end{array}$ \\
\hline $\begin{array}{c}\text { Vehicle Characteristics: (Ownership) } \\
\text { Strength of ownership }\end{array}$ & 0.211 & 0.142 \\
\hline $\begin{array}{l}\text { Types of goods } \\
\text { Foods and Beverage }\end{array}$ & $\begin{array}{l}-0.281 \\
0.213\end{array}$ & $\begin{array}{l}0.048 \\
0.138\end{array}$ \\
\hline $\begin{array}{c}\text { Types of freight suppliers } \\
\text { Key suppliers are Vendors, Cooperatives, Other } \\
\text { transport companies, } \\
\text { Key suppliers are distribution companies }\end{array}$ & & \\
\hline
\end{tabular}

\subsection{Ordinal Logistic Regression of Demand for a UFCC on the Significant Attributes of Transport Companies}

Since our data depository was already transformed into either ordinal or dichotomous variable while calculating the Spearman Rank Order Correlation Coefficient, no further transformation of data was required. Only the attributes having significant correlation coefficient were used in the ordinal logistics model of SPSS 17 version. The optimal model was found to have three significant independent variables. The pseudo R2 is above 0.22 in all three available methods (Cox and Snell 0.377, Nagelkerke 0.426, McFadden 0.219) which was taken to be acceptable considering similar researches (Regan, 2005, 0.22; Marcucci, 2008; 0.18).

Table 4. Parameter Estimates in Ordinal Logistic Regression

\begin{tabular}{|c|c|c|}
\hline Variables & Estimated coefficient & $\mathrm{p}$-value \\
\hline $\begin{array}{l}\text { Yearly Revenue is } 50 \text { Billion Won or below } \\
\text { Yearly Revenue is Over } 50 \text { Billion Won } \\
\text { Cargo Vehicles Capacity is }<8.5 \text { ton } \\
\text { Cargo Vehicles Capacity is } \geq 8.5 \text { ton } \\
\text { Freight providers are vendors, Other transport company, } \\
\text { co-operatives. } \\
\text { Freight providers are other than vendors, Other transport } \\
\text { company, co-operatives. }\end{array}$ & $\begin{array}{l}-1.789 \\
0 \mathrm{a} \\
1.759 \\
0 \mathrm{a} \\
.961 \\
0 \mathrm{a}\end{array}$ & $\begin{array}{l}.016 \\
.023 \\
.287\end{array}$ \\
\hline
\end{tabular}


The plum module of SPSS 17 identified two significant factors. Beta parameter for "Below 50B.won" yearly revenue (code 1) is -1.789 and yearly revenue "Over 50 B. won" is reference category. This indicates that the small revenue companies are less likely to choose UFCC compared to high revenue companies. In other word, inclusion of one single small revenue company will reduce the odd of choosing higher category of response for demand for UFCC by e-1.789. The second significant factor is the cargo vehicle capacity. Its positive beta 1.759 to lower group (light vehicle) indicates that light capacity vehicles are more like to choose UFCC than the heavy capacity vehicles. Every new inclusion of a light capacity vehicle prospect will increase the odd of choosing higher level preference for UFCC by e1.759. The remaining factor (key suppliers are brokers, cooperatives and other transport companies) is not significant in ordinal regression.

\subsection{Korean Transport Companies Key Characteristics that explain Demand for a UFCC}

From the three approaches used in this research, few common attributes have been found that show a significant prediction capability of demand for a UFCC. In our research, larger Korean transport companies have been found to be interested in using UFCC. Since previous Korean public logistics facilities and large-scale consolidation initiatives have been mostly populated by large companies, this kind of result is expectable. Large-capacity vehicles were found less related to the demand for a UFCC in all three methods $(-24 \%$ of heavy vehicles were interested; coefficient of correlation -0.493; and odd for small vehicle 5.807). The reason for this outcome could be the sufficient consolidation already generated by large vehicles in Korea. Moreover, there is no constraint for large cargo vehicles to maneuver in town. Since small vehicles could not get similar efficiency as large vehicles they are more interested for UFCC. Lastly transport companies that receive freight mostly from vendors, other transport company, and co-operatives are not interested in UFCC. The reason behind could be the fear of competition. These transport companies might be afraid of being replaced by UFCC's own delivery fleets. With a relaxed confidence level, container vehicles freight's, long term contracted vehicle's freights, foods and beverages, and distribution companies' freights have been found having positive demand for UFCC.

\section{Conclusion}

This research was designed identify the target customer groups for a UFCC in Korea. First step was to classify Korean transport companies based on their logistics functions. A classification framework was proposed after analyzing the Korean transport companies. The framework consists of 15 dimensions and many inter-related attributes. Korean transport companies' demand for a UFCC was surveyed in the form of ordinal stated preferences. Three kinds of analysis tools - descriptive percentile analysis, correlation analysis, and ordinal regression analysis helped for achieving a finer resolution. Correlation analysis has reduced classification dimensions/attributes into four. Ordered logistic model was built taking only three of them who were mutually independent. Ordinal regression model has found two of them significantly related with the demand for UFCC. Therefore, the final recommendation is to concentrate on those transport companies who generate larger revenue but use mainly light (small and medium) capacity cargo vehicles. With a little relaxation of the confidence level, other prospective customers may be food and beverage transporters, transporters of distribution companies' goods, container vehicles, and long-contracted \& self-owned vehicles. 
Besides, the companies dealing mostly container deliveries and express parcel deliveries and home deliveries may also be good prospect for UFCC.

The popularity of UFCC in Korea is inevitable due to the focus on a higher vehicle utilization rate and green logistics. Without the knowledge over the significant characteristics for identifying right customer and right goods, feasibility/suitability analysis of UFCC will be futile. And the decision of locating UFCCs in Korea may face the same fate of those failed UFCCs in EU. Usages of the factors identified in this research will produce more accurate estimation of demand for UFCC than any such estimation from general freight flows, economic growth, population, etc. which could lead to inflated result. This will be key for any future feasibility and location studies for the UFCC in Korea. Additional research can be designed to estimate the proportion of the business of those potential users that they are willing to channel through a UFCC, the cost structure at which they are willing to accept, receiver's satisfaction over getting freights from UFCC, community reaction toward UFCC, potential cost of operating a UFCC, size and layout of UFCC etc. The research findings have some limitation too. Due to budgetary constraints, data was collected from the transport companies who are mostly located in Seoul and Incheon area. A big budget project would help in accumulating data from all over the country. Also, during surveying, no price information for UFCC services were supplied to the respondent since main objective was to identify interested users not the price that they are willing to pay. With the price information, the research would not only identify the interested transport companies but also the companies who would prefer UFCC over private delivery at stipulated price structure.

This research possesses high implication for other countries that are having high congestion, road accident, and/or pollution in their urban area. The UFCCs in those countries could reduce freight traffic flows, accidents, congestion, air pollution, and thereby could reduce transportation cost for all the parties involved. Our understanding of private transport companies in choosing UFCC services will be very helpful for suitability analysis of UFCC in these countries.

\section{Acknowledgement}

This work was supported by National Research Foundation of Korea Grant Funded by the Korean Government (MOEHRD)(NRF-2011-413-B00008).

\section{References}

[1] J. Allen, G. Thorne and M. Browne, "BESTUFS-goods practice guide on urban freight transport", European Commission, (2007).

[2] OECD, Delivering the goods-21st century challenges to urban goods transport, OECD Publication, France, (2003).

[3] A. C Regan and T. F. Golob, "Trucking industry demand for urban shared use freight terminals", Transportation, vol. 32, no. 1, (2005), pp. 23.

[4] C. Woudsma, "Understanding the movement of goods", not people: Issues, evidence and potential. Urban Studies, vol. 38, no. 13, (2001), pp. 2439.

[5] L. Dablanc, "Goods transport in large European cities: Difficult to organize, difficult to modernize", Transportation Research Part A: Policy and Practice, vol. 41, no. 3, (2007), pp. 280-285.

[6] E. Marcucci and R. Danielis, "The potential demand for a urban freight consolidation centre", Transportation.vol. 35, no. 2, (2008), pp. 269-284.

[7] K. W. Ogden, "Urban goods movement: A guide to policy and planning”, Ashgate: Aldershot, (1992).

[8] Ministry of Construction and Transportation. Urban transportation policy for sustainable transportation in Korea, (2006).

[9] U. Kohler, "New ideas for the city -logistics project in Kassel", E. Taniguchi and R. G. Thompson (Eds.), Logistics Systems for Sustainable Cities, 321, Elsevier, Amsterdam, (2004). 
[10] M. Browne, M. Sweet, A. Woodburn and J. Allen, "Urban freight consolidation centres - final report", University of Westminister, (2005).

[11] K. Chwesiuk, K. Kijewska and S. Iwan, "Urban consolidation centres for medium-size touristic cities in the Westpormeranian region of Poland", Proceedings of the 6th International Conference on City Logistics, Madeina, Portugal, (2010).

[12] Y. Takahasi and T. Hyodo, "A simulation on the effect of physical distribution facilities in the Tokyo metropolitan region”, E. Taniguchi and R. G. Thompson (Eds.), City logistics 1, Proceedings of the 1st International Conference on City Logistics Cairns, Australia, (1999).

[13] C. Ambrosini and J. L. Routhier, "Objectives, methods and results of surveys carried out in the field of urban freight transport: An international comparison”, Transport Reviews, vol. 24, no. 1, (2004), pp. 57.

[14] A. Benjelloun and T. G. Crainic, "Trends, challenges, and perspectives in city logistics", Proceedings of the Transportation and Land Use Interaction, Bucharest, Romania, (2008).

[15] R. E. Weisbrod, E. Swiger, G. Muller, F. M. Rugg and M. K. Murphy, "Global freight villages: A solution to the urban freight dilemma", Proceedings of the 2002 Meeting of the Transportation Research Board, Washington, D.C., (2002) March 21-23.

[16] D. R. McDermott, "An alternative framework for urban goods distribution: Consolidation", Transportation Journal, vol. 15, no. 1, (1975), pp. 29.

[17] T. Nemoto, "Area-wide inter-carrier consolidation of freight in urban areas". Transport Logistics, vol. 1, no. 2, (1997), pp. 87.

[18] S. EU, "Sustainable urban and regional freight flows", ( No. TR 1053), (1998).

[19] E. Taniguchi and R. E. C. M. Vander Heiden, "An evaluation methodology for city logistics", Transport Reviews, vol. 20, no. 1, (2000), pp. 65.

[20] K. Kawamura and Y. Lu, "Evaluation of delivery consolidation in US urban areas with logistics cost analysis", Transportation Research Record: Journal of the Transportation Research Board, (2008).

[21] J. H. R. Van Duin, H. Quak and J. Manuzuri, "New challenges for urban consolidation centres: A case study in the Hague", Procedia Social and Behavioral Sciences, vol. 2, no. 6177, (2010).

[22] C. Finnegan, H. Finlay, M. O'Mahony and D. O'Sullivan, "Urban freight in Dublin city center, Ireland -survey analysis and strategy evaluation", Transportation Research Record: Journal of the Transportation Research Board, vol. 1906, no. 33, (2005).

[23] H. Quak and L. A. Tavasszy, "Customized solutions for sustainable city logistics; the viability of urban freight consolidation centres", Transitions towards sustainable mobility.Edited J. VanNunen, P. Rietveld and P. Huijbregts Springer, Berlin, (2011).

[24] T. VanRoijen and H. Quak, "Local impacts of a new urban consolidation centre - the case of binnenstadservice.nl", Proceedings of the 6th International Conference on City Logistics. Procedia Social and Behavioral Sciences, vol. 2, no. 5967, (2010).

[25] W. Young, S. G. Ritchie and W. K. Ogden, "Factors that influence freight-facility location preference", Transportation Research Record, vol. 747, no. 71, (1980).

[26] K. W. Ogden and W. Young, "A model of managers' preferences for location of freight facilities", Transportation Planning and Technology, vol. 8, no. 283, (1984).

[27] J. Yang and H. Lee, "An AHP decision model for facility location selection", Facilities.15(9/10), 241, (1997).

[28] C. L. Yang, S. P. Chuang, R. H. Huang and C. C. Tai, "Location selection based on AHP/ANP approach", Proceeding of the IEEE International Conference on Industrial Engineering and Management, (2008).

[29] Y. Zhang, K. O. Kwon and H. J. S. Kim, "Selecting a location for a city logistics facility: A fuzzy synthetic evaluation method", Journal of International Logistics and Trade, vol. 9, no. 1, (2011), pp. 115.

[30] J. Lim, J. and S. Seo, "Korean macroeconomic logistics costs in 2008", Seoul, Korea: The Korea Transport Institute, (2010).

[31] KOTI, Seoul: The Korean Transport Institute, Freight Transport Market Research Center, (2011).

[32] S.B. Seo and S.Y. Han, Developing the environment-Friendly collaboration method for logistics. Korean transport institute (KOTI), (2009).

[33] Harker, (1985).

[34] T J. Zlatoper and Z. Austrian, "Freight transportation demand: A survey of recent econometric studies", Transportation, vol. 16, no. 27, (1989).

[35] T. Crainic, "Operationas research models of intercity freight transportation: the current state and future research issues", Logistics and Transportation Review, vol. 23, no. 189, (1987).

[36] T. I. Friesz, P. A. Viton and R. L. Tobin, "Economic an Computational aspects of freight network equilibrium models: A systhesis”, Journal of Regional Science, vol. 25, (1985). 
[37] P. T. Harker and T. L. Friesz, "Prediction of intercity freight flows", Theory. Transportation Research, vol. 20B, no. 139, (1986).

[38] P. T. Harker and T. L. Friesz, "Prediction of intercity freight flows", II: Mathematical Formulations. Transportation Research, vol. 20B, no. 2, (1986), pp. 155.

[39] C. Winston, "A Disaggregate Model of the Demand for Intercity Freight Transportation", Econometrica, vol. 49, no. 4, (1981).

[40] T. Lee and J. Lee, "Policy Improvements for National Logistics Hub Considering the Characteristics of Users for Integrated Freight Terminals", Korean transport institute, (2009).

\section{Appendix}

\begin{tabular}{|c|c|}
\hline \multicolumn{2}{|r|}{ Table 1: Taxonomy of cargo items } \\
\hline $\begin{array}{c}\text { The } \\
\text { Primary Industry }\end{array}$ & $\begin{array}{l}\text { 101. Agricultural products } \\
\begin{array}{l}102 \text { Forest Products } \\
\text { 103. Seafood }\end{array}\end{array}$ \\
\hline Food \& Beverages & $\begin{array}{l}\text { 201. Beverages } \\
\text { 202. Tobacco Products }\end{array}$ \\
\hline Fiber. Clothing & $\begin{array}{l}\text { 301. Textiles, Except Apparel } \\
\text { 302. Clothing, apparel Accessories And fur products } \\
\text { 303. Leather, Bags And Footwear }\end{array}$ \\
\hline $\begin{array}{l}\text { Wood, paper. } \\
\text { Publications }\end{array}$ & $\begin{array}{l}\text { 401. Wood and Wood products (except furniture), } \\
\text { 402. Pulp, paper And Paper Products } \\
\text { 403. Print And Recording Media }\end{array}$ \\
\hline Petrochemical & $\begin{array}{l}\text { 501. Coke, coal, and refined petroleum products } \\
\text { 502. Compound \& Chemicals } \\
\text { 503 Rubber Products And Plastic Product }\end{array}$ \\
\hline Non-metallic material & 601. Non-metallic Mineral products \\
\hline Steel & 701. Primary Metal Product \\
\hline Machine & $\begin{array}{l}\text { 801. Fabricated Metal Products: Except Machinery and Furniture } \\
\text { 802. Other machinery and equipment manufactured }\end{array}$ \\
\hline $\begin{array}{l}\text { Electric and } \\
\text { Electronic }\end{array}$ & $\begin{array}{l}\text { 901. Electronic components, computer, radio, television, and Communication } \\
\text { equipment } \\
\text { 902 Electrical and Equipment Product } \\
\text { 903. Medical, precision, optical instruments, watches and clock }\end{array}$ \\
\hline Transport Equipment & $\begin{array}{l}\text { 1001. Car And Trailers } \\
\text { 1002. Other transport Equipment }\end{array}$ \\
\hline Other & $\begin{array}{l}\text { 1101. Furniture products 1102. Other Products } \\
\text { 1103. Recycled materials }\end{array}$ \\
\hline Non-manufacturing & $\begin{array}{l}\text { 1201. Coal Minerals } 1202 . \text { Limestone minerals } \\
\text { 1203. Crude Oil And Natural Gas extraction products } \\
\text { 1204: Metals and Minerals } 1205 . \text { Non-metallic minerals }\end{array}$ \\
\hline Containers, Courier & $\begin{array}{c}\text { 1301 Red (适) container (Not checked contents), } \\
\text { 1302. Empty (空) container } \\
\text { 1303: Courier (Contents Confirmation not possible) }\end{array}$ \\
\hline
\end{tabular}


Table 2. Operational Dimensions and Attributes for Classifying Korean Transport Companies

\begin{tabular}{|c|c|}
\hline Dimensions & Attributes \\
\hline Company revenue size & 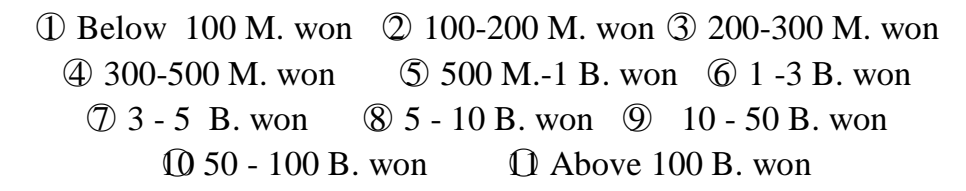 \\
\hline \multicolumn{2}{|l|}{ Number of employee } \\
\hline \multicolumn{2}{|l|}{ Location } \\
\hline $\begin{array}{l}\text { Revenues by alternative types } \\
\text { of freight vehicles }\end{array}$ & $\begin{array}{l}\text { (1) General (cargo) type (2) Dump truck } \\
\text { (tank lorry etc.) (4) Container / Trailer }\end{array}$ \\
\hline $\begin{array}{l}\text { Capacity of general / cargo } \\
\text { vehicles }\end{array}$ & $\begin{array}{l}\text { (1) Below } 1 \text { ton (2) Over } 1 \text { ton } \sim 2.5 \text { ton (3) Over } 2.5 \text { ton } \sim 8.5 \text { ton } \\
\begin{array}{ll}\text { (4) Over } 8.5 \text { ton } \sim 15 \text { ton } & \text { (5) Over } 15 \text { ton (excl. dump truck) }\end{array}\end{array}$ \\
\hline Types of vehicle ownership & $\begin{array}{c}\text { (1) Owned (2) Contracted (over } 1 \text { month) (3) Contracted (below } 1 \\
\text { month) }\end{array}$ \\
\hline Trip length & (1) Within city (2) Within Province (3)Domestic long distance \\
\hline Assortment of goods & $\begin{array}{c}\text { (1) } 1 \text { (2) } 2-5 \text { (3) 6-9 (4) } 10-13 \\
\text { (Total } 13 \text { categories of goods, see appendix A) }\end{array}$ \\
\hline Goods preferred & The list of goods is given in the appendix A \\
\hline Avg. \# of freight providers & (1) below 5 (2) 6-20 (3) $21-50$ (4) $51-100$ (5) over 100 \\
\hline Types of freight providers & $\begin{array}{l}\text { (1) Vendor / Other transport company /Co-operatives } \\
\text { (2) Manufacturing companies (3) Distribution companies } \\
\text { (4) Final customer (Home, company) }\end{array}$ \\
\hline $\begin{array}{l}\text { Origin and destination of } \\
\text { freights }\end{array}$ & $\begin{array}{l}\text { (1)Manufacturing Co.(Plant, warehouse) } \\
\text { (2) Distribution Co.(Show room, Store) (3)Ports (4)ICD/ Railroad CY } \\
\text { (5) Other region Logistics/Freight terminal } \\
\text { 6 Final Consumer (Home, Company) (7) Others }\end{array}$ \\
\hline $\begin{array}{l}\text { Level of consolidation per } \\
\text { trip }\end{array}$ & (1)12)2-5(3)6-10 (4)11-20 (5) over 20 \\
\hline
\end{tabular}




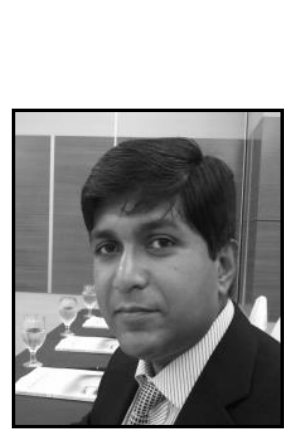

\section{Authors}

Mohammad Khaled Afzal, is associate professor of Department of Management studies at Chittagong University, Bangladesh. He got his Ph.D degree from Inha university under supervision of Dr. Yong Jin Kim.

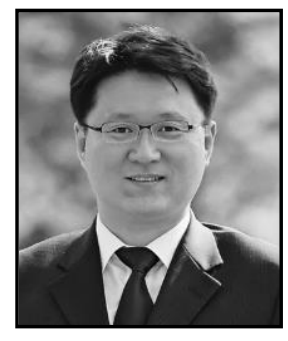

Yong Jin Kim, is currently professor of Asia Pacific School of Logistics and Graduate School of Logistics at Inha University in Korea. $\mathrm{He}$ also serves as deputy director of Jungseok Research Institute of international logistics and trade. He was educated at the Seoul National University where he was awarded the BS and MS degree in the urban engineering in 1993 and 1996, respectively. He got his Ph.D degree at the University of Texas at Austin majoring Transportation and Logistics System supervised by Dr. Mahmassani and Dr. Jaillet.

Before joining Inha, he was a research fellow at the Korean Transport Institute. His research interests focus on modeling and analysis of freight transportation systems, commercial fleet management problems, simulation. 
International Journal of Transportation

Vol. 2, No. 2, (2014) 